BUJSS

11/1 (2018), 24-34 DOI: 10.18221/bujss.377135

\title{
YÖNETİCİLERDE FİNANSAL PAZARLAMA ALGISININ ÖLÇÜMÜ ${ }^{1}$
}

\author{
Barış Batuhan GEÇİT ${ }^{2}$
}

\begin{abstract}
ÖZ
Günümüz rekabet koşullarında işletmelerin daha iyi yönetilebilmesi adına çeşitli farklı stratejiler denenmektedir. Daha iyi bir yönetim için de multi disipliner, bir başka ifadeyle birden fazla disiplinin bir arada olduğu çalışmalar önemli bir değişken haline gelmiştir. İşletmenin fonksiyonları arasında yer alan pazarlama ve finans birlikte hareket ederek işletmeler için fayda yaratabilmektedir. Bu araştırmada da bu iki fonksiyonun entegre çalı̧̧asına yönelik literatür ele alınmış ve yöneticilerin finansal pazarlama kavramına ilişkin bilinçleri ölçülmüştür. Bu doğrultuda pazarlama karması olarak bilinen ürün, tutundurma, dağıtım ve fiyat stratejilerinin; yöneticiler tarafindan finansal pazarlama perspektifinde değerlendirilip değerlendirilmediği anket metodolojisi ile ölçülmüştür. Elde edilen sonuçlar doğrultusunda yöneticiler fiyatlandırma ve dağıtım kavramlarında finansal pazarlama bakış açısı ile stratejilerini yürütmekteyken; ürün ve tutundurma kavramlarında finansal pazarlama bakış açısı ile stratejilerini yürütmemektedirler.
\end{abstract}

Anahtar Kelimeler: Finans, Pazarlama, Finansal Pazarlama, Yönetici

\section{MEASUREMENT OF THE FINANCIAL MARKETING PERCEPTION OF MANAGERS}

\begin{abstract}
In today's competitive environment, various strategies are being tested for the better management of businesses. For better management, multidisciplinary work, combination of multiple disciplines have become an important variable. As functions of the business administration; marketing and finance can work together to create benefit for businesses. In this study, the literature on the integrated operation of these two functions was discussed and the managers' awareness of the concept of financial marketing was measured. In this direction, product, promotion, distribution and price strategies, known as marketing mix, were measured by managers in a financial marketing perspective. In the direction of the results obtained, while the managers are carrying out the strategies within the perspective of financial marketing in terms of pricing and distribution; they do not carry out their strategies within the perspective of financial marketing in terms of product and promotion..
\end{abstract}

Keywods: Finance, Marketing, Financial Marketing, Manager 


\section{BUJSS}

11/1 (2018), 24-34

\section{GíRíş}

Disiplinler arası çalı̧̧malar günümüzde işletmelerde ve akademik çalı̧̧malarda sıklıkla görülmektedir. Sosyal bilimler ile fen bilimleri arası çalışmalar olduğu gibi, işletme ve iktisat gibi sosyal bilim alanlarında da disiplinler arası çalışmalar yapılmaktadır. Örneğin turizm pazarlaması isimli alan, turizm alanı ile pazarlama alanının ortak bir çalışma alanıdır.

Günümüzde işletmeler ve işletmeciler pazarlama, üretim, yönetim, finans, insan kaynakları, muhasebe gibi alt dallara ayrılarak, uzmanlaştıkları alanlarda faaliyet göstermektedirler. Firmalarda pazarlama çalışanları, insan kaynakları müdürleri gibi bu dalların profesyonelleri yer almaktadır. Ancak bu alanların bir arada çalı̧smaları, ortak faaliyetler göstermeleri ve birbirlerine olumlu etkilerde bulunmaları gerekmektedir. Bunun yanı sıra entegre çalıştıkları da görülmektedir. Çünkü tüm bu alt dallar işletme için değer yaratmayı hedeflemektedir ve faaliyetlerinde birbirlerini etkileyen yönleri belirleyerek, ortak pozitif amaç için entegre çalışmaları olumlu yönlü etki yapacaktır.

Bunlardan pazarlama ve finans; işletme stratejilerinin oluşturulması, uygunlanması ve başarıyla sürdürülmesi ve tüm bunların sonucunda da değer yaratılması anlamında son derece önemli iki kavramdır.

\section{FINANSAL PAZARLAMA YAKLAŞIMI}

Firmalar için uzun vadeli başarının ve hedeflenen konumlandırmanın neticesi rekabetçi avantajdır. Rekabetçi avantaj; marka oluşturma, müşteri sadakati, pazar bölümlendirmesi gibi pazarlama çabaları ile olur. Tüm bu pazarlama çabaları da büyük çaplı yatırımları gerektirir ve bu yatırımlar da firmalar için risk oluşturmaktadır. Tüm bu çabaların finansmanının sağlanması ve onaylanması için finansal pazarlama yaklaşımı gereklidir.

Türkiye'de yazılan tezler tarandığında finansın pazarlamayı içerdiği, pazarlamanın da finansı içerdiği herhangi bir teze rastlanamamış olmak ile beraber finansal pazarlama isimli bir kitap, makaleye rastlanmamıştır. Finansal Satış (Özkan, 2015) Finansal Satış isimli kitap finansal pazarlamanın işlendiği sayılı kaynaklardandır. Uluslararası literatürde de bu konuda çok fazla çalışmaya rastlanmamıştır.

Integrating Rules and Inheritance Networks in a Knowledge-Rased Financial Marketing Consultation System isimli makalede Daly, Kastner ve Mays (1988) yılında, nerdeyse 30 yıl öncesinden finansal pazarlama ile ilgili ampirik modeller sunmuştur.

Sayılı sayıda var olan kaynaklar finansal pazarlama kavramının işletme açısından önemini ortaya koymaktadır. Finansal pazarlama akademik olarak fazla çalışılmamış ve akademisyenler tarafından üzerinde çok sıklıkla durulmamış bir konudur, ancak işletmelerin sürdürülebilir başarısı ve değer yaratması için vazgeçilmez bir kavramdır.

Finansal pazarlama işletmeler ve literatür için öylesine niş bir kavramdır ki; American Marketing Association sözlüğü gibi akademik pazarlama kaynaklarında pazarlamanın bir tanımı veya sayfası yer almamaktadır. 


\section{BUJSS}

11/1 (2018), 24-34

Oldukça sayılı kaynak var olmakla birlikte, finnans ve pazarlama literatürde multidisipliner olarak, iki farklı anlamda ele alınmıştır. Birincisi bu çalışmada bahsedildiği şekilde pazarlama faaliyetlerinin finansal analizler ile yürütülmesini savunan kavramdır, ikincisi ise finansal araçların pazarlanmasını araştıran kavramdır.

Finansal araçların pazarlanması ağırlıklı olarak literatürde "marketing of financial services" olarak, pazarlama faaliyetlerinin finansal değerlendirmeler ile yürütülmesi ise "financial marketing” olarak geçmektedir.

Finansal araçların pazarlanması (marketing of financial services); bonoların, menkul kıymetlerin, hisse senetlerinin yatırımcılar tarafından tercih edilmesini sağlamayı amaçlayan bir alandır. $\mathrm{Bu}$ araştırmada kullanılan finansal pazarlama (financial marketing) ise pazarlamanın faaliyetlerinin finans perspektifinde yürütülmesidir. İki kavram kelime olarak çok benzese de gerek sektörel uygulamada, gerek ise akademik bir çalışmada bambaşka anlamlara gelen iki kavramdır.

\section{FINANS İLE PAZARLAMANIN İLIŞKİSi}

Kaya (2015) öncelikli olarak pazarlamanın stratejilerinin finansal perspektiften uygulanışını anlatmıştır. Pazarlamacılar, pazarlama ölçümlerini finans ölçümleriyle ilişkilendirmelidirler. Pazarlamacılar pazarlama bütçelerindeki her kalemin gerekliliğini doğrulamalı ve her birinin hisse değerine nasıl bir katkısı olduğunu gösterebilmelidir. Buna finansal pazarlama denmektedir. Finansal pazarlama aynı zamanda da, her türlü finansal araçların, ürünlerin ve hizmetlerin pazrlanmasını kapsamaktadır.

Finansal pazarlama yaklaşımı, pazarlamanın iki birbiriyle yakından ilgili kavramı ile ilgili finansal bir çalışmayı gerektirmektedir. Para harcamak için bir taahhüt vermeden önce, çok titiz bir finansal değerlendirme yapılmalıdır. Finansal değerlendirme teklif halindeki harcama veya gider ile potansiyel faydaları, riski de göz önünde bulundurarak mukayese eder. Finansal değerlendirme sürecinde, pazarlama veya pazar araştırması departmanı da devrede olmalıdır.

Öte yandan geçmiş finansal verilerin incelenmesi gelecek için sağlıklı sonuçlar verebilir. Geçmiş finansal veriler incelenip, gelecek pazarlama faaliyetleri ile ilgili aşağıdakiler göz önünde bulundurularak strateji geliştirilmelidir:

- Planlamanın temeli için finansal analizi

- Hedefler ve amaçları belirlemek için finansal planlama

- Kararların sonuçlarını görüntülemek, sonuçların doğruluğunu görmek ve mümkünse hataları düzeltmek üzere finansal kontrol 


\section{BUJSS}

11/1 (2018), 24-34

Pazarlama açısından, tüm bu hedeflerin başarılması ölçülebilir olmalıdır. Örneğin marka farkındalığındaki bir artış reklam vermeden önce ve sonrasında ölçülmelidir. Böylelikle pazarlamanın amaçlarına ulaşıp ulaşmadığı, bir başka ifadeyle hedeflenen tüketici grubunda marka farkındalığını \%30'dan \%40'a çıkarmayı başarıp başaramadığı kanıtlanmış olur. Finansal pazarlamanın anahtar sorusu "Bu reklama X Milyon dolar harcamaya değer mi?" dir. Çok net bir şekilde, ne kadar finansal kontrol gerektirir ise gerektirsin, yatırım taahhütü yerine getirilmeden, reklam harcaması yapılmadan önce değerlendirilmesi gerekmektedir (Ward, 2003).

İşletmeler kuşkusuz geniş kitlelere ulaşma olanağı buldukları her platformda reklam vermek isterler. Ancak bu da işletmenin finansal dengelerinde ciddi bir maliyettir ve getirisi; gerek maddi, gerek ise marka değeri olarak reklam harcamalarının ötesine geçer ise, bahsi geçen reklam harcamalarını yapmanın gereği yoktur. Bu açıdan pazarlama karmasının tutundurma elemanı, finansal bir perspektif dahilinde yapılmalıdır.

İşletmeler aynı zamanda pazarlama karmasının iki diğer bileşeni olan ürün ve dağıtım stratejilerinde de ellerindeki kaynakları verimli kullanmak zorundadırlar. Tüketici talebine bakılmaksızın, tüm üretim faaliyetleri seferber edilerek yapılacak bir üretim firmanın sonunu getirebilir. Miktarsal olarak olduğu gibi, kalite anlamında da gereğinden iyi veya kötü bir ürün üretmek ve finansal kaynakları bu doğrultuda kullanmak; firmanın beklediği neticeleri elde edememesine yol açabilir.

Dağıtım açısından da firmaların finansal kaynakları göz önünde bulundurarak pazarlama faaliyetlerini sürdürmesi gerekmektedir. En uygun fiyatlı aracının veya dağıtılacak kanalın bulunup, o kanal ile dağıtımın yapılması işletmenin belirli finansal dönemde avantajlı olmasını sağlayacaktır.

Günümüzde marka kavramı bile finansal olarak ölçülebilen bir kavramdır. Brandz (2017) her yıl Dünyanın En Değerli Markaları listesini oluşturmaktadır. Brandz bu listeyi oluştururken markaların finansal marka değerlerini temel almaktadır ve metodolojisinde ağırlıklı olarak finansal veriler yer almaktadır. Bu da ortaya koyuyor ki bir pazarlama alt başlığı olarak gözüken marka değeri kavramı bile esasında finansal veriler ile ölçülmektedir ve bu konuda da finans ile pazarlama entegre vaziyette çalışmaktadır.

Bir inşaat şirketi ve akaryakıt istasyonu sahibi girişimci ile yapılan mülakatta, kişi finansal pazarlamayı düşünerek ticari faaliyetlerini yürüttüğünü söylemiştir. Benzinlik için yapmış olduğu promosyon harcamaları (yıkama fişleri, hediyeler..) sonucunda yıl sonunda bu harcamalar ve getiriler arasındaki dengede \%25 karlı çıktığını ileri sürmüştür. 


\section{BUJSS}

11/1 (2018), 24-34

Finansal pazarlamanın başarı ile yürütülüp yürütülmediğinin anlaşılması da gereklidir. Bunun için ön analizler ve sonuç analizleri yapılarak; nasıl harcamalar yapılmalı ve ne elde edildi gibi konularda sonuçlar elde edilmelidir. Ward (2013) finansal pazarlama için üç tip analiz yapılabileceğini öne sürmüştür. Bunlar pazarlama literatüründe de kullanılan kavramlarıdır:

- SWOT Analizi

- Boston Matriksi

- Nakit Akışı Matriksi

Sonuç olarak firmaların kendi lehlerine pazarı değiştirmek, yönlendirmek ve etkilemek için yaptıkları faaliyetleri; varlıklar ve yükümlülükleri maksimize ederek yönetmesi, bir başka ifade ile başarılı bir finansal pazarlama politikası izlemeleri gerekmektedir (Özkan, 2015, s.19-22).

\section{VERİ SETİ VE METODOLOJI}

Araştırma Ankara ve İstanbul şehirlerindeki şirket yöneticileri üzerinde anket yöntemi ile uygulanmıştır. 40 kişi üzerinde uygulanan ankette cinsiyet olarak, 30 kişi (\%75) erkek, 10 kişi (\%25) kadındır. Yaş olarak; 10 kişi (\%25) 25-29 yaş aralığında, 6 kişi (\%15) 30-34 yaş aralığında ve 24 kişi (\%60) 35 yaş ve üzeri yaştadır. Eğitim bilgileri ise; 1 kişi $(\% 2,5)$ ön lisans mezunu, 21 kişi $(\% 52,5)$ lisans mezunu, 15 kişi $(\% 37,5)$ yüksek lisans mezunu, 3 kişi $(\% 7,5)$ doktora mezunudur. Anket uygulanan yöneticilerden 25 'i $(\% 62,5)$ Ankara'da ikamet etmekteyken, 15’i $(\% 37,5)$ İstanbul'da ikamet etmektedir.

\subsection{HIIPOTEZLER}

H1: Ürün ile ilgili stratejilerde yöneticiler finansal pazarlama kavramı bakış açısı ile stratejilerini yürütürler.

H2: Dağıtım ile ilgili stratejilerde yöneticiler finansal pazarlama kavramı bakış açısı ile stratejilerini yürütürler.

H3: Fiyatlandırma ile ilgili stratejilerde yöneticiler finansal pazarlama kavramı bakış açısı ile stratejilerini yürütürler.

H4: Tutundurma ile ilgili stratejilerde yöneticiler finansal pazarlama kavramı bakış açısı ile stratejilerini yürütürler.

H5: Yöneticiler finansal pazarlama kavramanın marka imajlarına etki edeceğini düşünürler. 


\section{BUJSS}

11/1 (2018), 24-34

\subsection{NORMALLİK DAĞILIMI}

Normallik dağılımı, istatistiksel analizlerde elde edilen verilerin anakütle için genellenebilirliğini sağlamaktadır (Kavak, 2013, s.256).

Sorular için Skewness ve Kurtosis değerleri şu şekildedir (Tablo 1):

Tablo 1: Skewness ve Kurtosis Değerleri

Shapiro-Wilk

\begin{tabular}{|l|l|l|}
\hline Istatistik & Df & Sig. \\
\hline, 965 & 40 &, 241 \\
\hline
\end{tabular}

Descriptives

\begin{tabular}{|l|l|l|}
\hline & Istatistik & Standart Sapma \\
\hline Skewness (Çarpıklı) &,- 200 &, 374 \\
\hline Kurtosis (Basıklık) &,- 729 &, 733 \\
\hline
\end{tabular}

Verilerin normallik dağılımları incelendiğinde; verilerin normal dağıldıklarının kabul edilebilmesi için Kolmogorov-Smirnov ve Shapiro-Wilk'deki p değerlerinin 0,05'den büyük olması gerekmektedir. Analiz sonuçlarında $\mathrm{p}$ değerleri ağırlıklı olarak 0,05 'den yüksek çıkmıştır. Bunun yanı sıra verilerin normallik dağılımı için geçerli sayılan bir başka değer olan Skewness ve Kurtosis değerlerine bakıldığında; verilerin çok büyük bir kısmının kabul edilebilir değer olan -3 ve +3 sınırları içerisinde olduğu görülmektedir. Bu doğrultuda iki tabloda da veriler normal dağılmaktadır şeklinde yorumlanabilmektedir

\subsection{KORELASYON ANALIZİ}

Korelasyon analizi, değişkenler arasındaki ilişkinin gücünü bulup yorumlamak amacıyla kullanılır (Büyüköztürk, 2016, s.31). Korelasyon analizinde, her bir değişken arasında Pearson Correlation değerlerine bakılır. Bu değerler 1,000'a yaklaştıkça değişkenler arası daha güçlü bir ilişkiden, ,000'a yaklaştıkça ise değişkenler arası daha güçsüz bir ilişkiden söz edilmektedir.

Korelasyon analizi tablosu şu şekildedir (Tablo 2): 
BUJSS

11/1 (2018), 24-34

Tablo 2: Korelasyon Analizi

\begin{tabular}{|c|c|c|c|c|}
\hline & Urün & Dağıtım & Tutundurma & \begin{tabular}{|l|} 
Fiyat \\
\end{tabular} \\
\hline \multirow[t]{3}{*}{ Urün } & $\begin{array}{l}\text { Pearson } \\
\text { Correlation }\end{array}$ & 1 & ,694 & , 477 \\
\hline & Sig. (2-tailed) & & ,000 & ,002 \\
\hline & $\mathrm{N}$ & 40 & 40 & 40 \\
\hline \multirow[t]{3}{*}{ Dağıtım } & $\begin{array}{l}\text { Pearson } \\
\text { Correlation }\end{array}$ & ,694 & 1 & ,271 \\
\hline & Sig.(2-tailed) & ,000 & & ,091 \\
\hline & $\mathrm{N}$ & 40 & 40 & 40 \\
\hline \multirow[t]{3}{*}{ Tutundurma } & $\begin{array}{l}\text { Pearson } \\
\text { Correlation }\end{array}$ & ,477 & 271 & 1 \\
\hline & \begin{tabular}{|l|} 
Sig.(2-tailed) \\
\end{tabular} & ,002 & ,091 & \\
\hline & $\mathrm{N}$ & 40 & 40 & 40 \\
\hline \multirow[t]{3}{*}{\begin{tabular}{|l|} 
Fiyat \\
\end{tabular}} & $\begin{array}{l}\text { Pearson } \\
\text { Correlation }\end{array}$ & ,516 & ,508 &, 325 \\
\hline & \begin{tabular}{|l|} 
Sig.(2-tailed) \\
\end{tabular} & ,001 & ,001 & ,040 \\
\hline & $\mathrm{N}$ & 40 & 40 & 40 \\
\hline
\end{tabular}




\section{BUJSS}

11/1 (2018), 24-34

Yapılmış olan analiz sonucunda;

Tutundurma ve dağıtım dışında tüm diğer faktörler arasında anlamlı bir ilişki olduğu sonucu elde edilmiştir.

Tablodaki Pearson Correlation verileri değișkenlerin birbirleri ile olan ilișkilerinin gücünü ortaya koymaktadır.

Bu tabloya göre yöneticilerin finansal pazarlama stratejisi uygulamalarında; ürün ile dağıtım arasında \%69,4'lük bir korelasyon, ürün ile tutundurma arasında \%47,7’lik bir korelasyon, ürün ile fiyat arasında da $\% 51,6$ 'lik bir korelasyon vardır.

Dağıtım ile; tutundurma arasında $\% 27,1$ 'lik, fiyat ile \%50,8'lik bir korelasyon vardır.

Tutundurma ile fiyat arasında ise $\% 32,5$ ' lik bir korelasyon vardır.

\subsection{REGRESYON ANALIZI}

Regresyon analizi tablosu şu şekildedir (Tablo 3):

Tablo 3: Regresyon Analizi

\begin{tabular}{|l|r|r|r|r|r|}
\hline Model & \multicolumn{1}{|c|}{ Kareler } & df & Ort. Kare & F & Sig. \\
& Toplam & & & & \\
\hline Regresyon & 13,239 & 4 & 3,310 & 7,456 &, 000 \\
\hline Kalan & 15,536 & 35 &, 444 & & \\
\hline Toplam & 28,775 & 39 & & & \\
\end{tabular}

Katsayılar

\begin{tabular}{|c|c|c|c|c|c|}
\hline & \multicolumn{2}{|l|}{ Std. Katsayılar } & \multirow{2}{*}{$\begin{array}{l}\text { Std. } \\
\text { Katsayılar } \\
\text { Beta }\end{array}$} & \multirow[t]{2}{*}{$\mathrm{T}$} & \multirow[t]{2}{*}{ Sig. } \\
\hline & B & Std.Error & & & \\
\hline (Constant) & 2,202 & ,363 & & 6,073 &, 000 \\
\hline Fiyat & ,278 &, 117 &, 358 & 2,372 & ,023 \\
\hline Urün &,- 163 & , 129 &,- 244 & $-1,263$ &, 215 \\
\hline Dağıtım &, 316 & ,111 &, 510 & 2,844 & ,007 \\
\hline Tutundurma &, 132 & ,098 & ,192 & 1,341 & ,189 \\
\hline
\end{tabular}




\section{BUJSS}

11/1 (2018), 24-34

Regreasyon analizi sonuçlarına göre; üstteki ANOVA tablosunda p (sig.) değeri, modelin kabul edilmesi için gerekli olan en yüksek değer olan 0,05'den düşük çıktığı için model kabul edilmiştir.

Bir alttaki tabloda ise her bir değişkenin için yöneticilerin finansal pazarlama kararlarına verdikleri önem ve bunun finansal pazarlama stratejilerine etkileri yer almaktadır.

Sonuçlara göre fiyatlandırma için yöneticilerin finansal pazarlama kavramına önem verdikleri gözlemlenmiştir $(\mathrm{p}<0.05)$.

Ürün için ise hem p değeri anlamsız çıkmıştır, hem de beta değeri negatif yönlü çıkmıştır. Bunun anlamı şudur: ürün ile finansal pazarlama arasındaki bu önerme kabul edilmiş olsaydı negatif yönlü bir ilişki ortaya çıkacaktı $(\mathrm{p}>0.05)$.

Dağıtım için de önerme anlamlı çıkmıştır $(\mathrm{p}<0.05)$.

Tutundurma için ise önerme anlamsız çıkmıştır $(\mathrm{p}>0.05)$.

$\mathrm{Bu}$ sonuçlara göre; yöneticiler ürün ve tutundurma faaliyetlerinde finansal pazarlamayı benimsememekteyken, dağıtım ve fiyat faaliyetlerinde finansal pazarlamayı benimsemişlerdir.

Marka - Finansal Pazarlama İlişkisi

Tablo 4: Marka- Finansal Pazarlama Regresyon Analizi

\begin{tabular}{|l|l|l|l|l|l|}
\hline \multirow{2}{*}{ Model } & \multicolumn{2}{|l|}{$\begin{array}{l}\text { Standartlaștırılmamıș } \\
\text { Katsayılar }\end{array}$} & $\begin{array}{l}\text { Standartlaștırılmıs } \\
\text { Katsayılar }\end{array}$ & T & Sig. \\
\cline { 2 - 6 } & B & Std.Error & Beta & & \\
\hline (Constant) & 1,968 &, 996 & & 1,977 &, 055 \\
\hline FinPaz &, 288 &, 248 &, 185 & 1,163 &, 252 \\
\hline
\end{tabular}

Öte yandan modelde pazarlama karmasının bir ana elemanı olmadığ 1 için yer verilmeyen marka kavramı ile finansal pazarlama arasındaki etki de ölçülmüştür. Bu doğrultuda marka kavramı ile finansal pazarlama arasında anlamlı bir ilişki yoktur.

\subsection{HIPOTEZ SONUÇLARI}

H1: Ürün ile ilgili stratejilerde yöneticiler finansal pazarlama kavramı bakış açısı ile stratejilerini yürütmezler (Red).

H2: Dağıtım ile ilgili stratejilerde yöneticiler finansal pazarlama kavramı bakış açısı ile stratejilerini yürütürler (Kabul).

H3: Fiyatlandırma ile ilgili stratejilerde yöneticiler finansal pazarlama kavramı bakış açısı ile stratejilerini yürütürler (Kabul).

H4: Tutundurma ile ilgili stratejilerde yöneticiler finansal pazarlama kavramı bakış açısı ile stratejilerini yürütmezler (Red).

H5: Yöneticiler finansal pazarlama kavramanın marka imajlarına etki edeceğini düşünmezler (Red). 
BUJSS

11/1 (2018), 24-34

\section{BULGULAR}

Hipotez sonuçları doğrultusunda yöneticilerin ürün ve tutundurma kavramlarına finansal pazarlama perspektifinden bakmadıkları ve finansal tablolarında negatif bir netice ile sonuçlanacak olsa da ürün için ve tutundurma için harcama yapmaktan kaçınmayacakları ortaya çıkmışıı. Bir başka ifadeyle, tutundurma kavramı açısından geniş kapsamlı bir internet reklamı hazırlamaktan ve uygulamaya koymaktan, o finansal dönemde zarar edeceklerini bilseler bile çekinmeyebilirler.

Öte yandan dağıtım ve fiyatlandırma politikalarıı finansal pazarlama bakış açısı ile gerçekleştirirler. Örneğin ürünlerini daha uzak yerlere ulaştırmak için finansal açıdan kendilerini zarar ettirecek giderleri göze almazlar.

Finansal pazarlama kavramının marka imajlarına herhangi bir etkisi olacağı konusunda sorulan soruya da olumsuz cevap veren yöneticiler, finansal pazarlama perspektifinden faaliyet yürütmenin markalarını yücelteceği görüşüne sahip değildirler

\section{SONUÇ, ÖNERILLER VE KISITLAR}

Çalışma daha fazla yönetici üzerinden ölçülerek daha genellenebilir sonuçlar elde edilebilirdi. Ayrıca kaynak sayısının eksikliğinden ötürü kaynakça yeterince zengin olamadı. Bir başka ifadeyle konu o kadar az çalışlmış bir konu ki; kaynakça kısıtlı kalmak zorunda oldu.

Bundan sonraki çalışmalarda finansal pazarlamanın yönetici perspektifinden değil de, finansal ölçümlerle efektifliği ölçülebilir. Gerçek bir işletmeden pazarlama yatırımları alınarak, belirli bir finansal dönemde ne elde ettikleri ölçülebilir.

İşletme literatüründe oldukça az çalışılmış ve nerdeyse hiç kitabı olmayan ve oldukça sınırlı sayıda makalesi olan finansal pazarlama konusunda literatüre yeni bir çalışma kazandırılmış olundu. Türkiye'de hali hazırda ismi Finansal Pazarlama olan bir kitap bulunmamaktadır. Araştırma, literatürde az çalışılmış bir konuya ve alana odaklanmıştır. Dolayısıyla literatüre katkı sağlayacağı düşünülmektedir. Özellikle Türkiye için çok az çalışılmış bir konudur ve literatüre katkı sağlayacağı düşünülmektedir. 


\section{BUJSS}

11/1 (2018), 24-34

\section{KAYNAKÇA}

Büyüköztürk, Ş. (2016). Sosyal Bilimler İçin Veri Analizi El Kitabı. 14. Baskı. Ankara, Pegem Akademi.

Daly, T., Kastner, J., \& Mays, E. (1988, January). Integrating Rules and Inheritance Networks in a Knowledge-based Financial Marketing Consultation System. In System Sciences, 1988. Vol. III. Decision Support and Knowledge Based Systems Track, Proceedings of the Twenty-First Annual Hawaii International Conference on (Vol. 3, pp. 496-500). IEEE.

Kaya, İ. (2015). Pazarlama Bi’Tanedir!. Babıali Kültür Yayıncılık.

Kavak, B. (2008). Pazarlama ve Pazar Araştırmaları. Ankara: Hacettepe Üniversitesi Yayınları.

Lehmann, D. (2002). Linking Marketing Decisions to Financial Performance and Firm Value. MSI Executive Overview, 1-5.

Özkan. T. (2015). Finansal Satış. İstanbul:Papatya Yayınevi.

Ward, K. (2003). Marketing Finance. p:3.

Ward, K. (2013). Financial Aspects of Marketing. Routledge. 